\title{
Cultura vira emprego ${ }^{1}$
}

Belmira Magalhães*

Gabriel UFAL**

Resumo: Este artigo realiza uma análise do Programa Cultura Viva, do Ministério da Cultura, enfatizando o papel da mulher na condução de projetos sociais e mostrando a relação que esse tipo de atividade possui com a problemática do desemprego da população jovem brasileira. Os dados demonstram que não há nenhuma melhoria para essa população através das atividades desenvolvidas pelos "Pontos de Cultura", da mesma forma que revelam a não resolução do problema da marginalização da cultura popular, apregoada pelo Programa. Como suporte das análises utilizamos as teorias sociológicas e de análise do discurso. Pudemos concluir que não há uma política que leve em conta as diferenças de gênero, sendo que o programa acaba por fazer parte da política econômica do governo Lula, que trata as disparidades sociais através de políticas compensatórias.

Palavras-chave: Gênero e projetos sociais. Cultura e desemprego. Cultura popular, gênero e desigualdades sociais.

Abstract: This article examines the Program "Cultura Viva" of the Ministry of Culture, emphasizing the role of women in the conduct of social projects and showing the relationship that such activity has to the problem of unemployment of young population segments in Brazil. The data show that there is no improvement for this population through the developed activities by the "Points of Culture", just as revealing the failure to resolve the problem of marginalization of popular culture, heralded by the program. Analysis had the support of sociological theories and theories of discourse analysis. We can conclude from the lack of a policy that takes into account gender differences and that the program is part of the economic policy of the Lula government, which deals with social disparities through compensatory policies.

Key words: Gender and social projects. Culture and unemployment. Popular

${ }^{1}$ Este artigo é o resultado de mais uma pesquisa realizada pelo Núcleo de pesquisa sobre a condição feminina, da UFAL e do Grupo de Pesquisa Gênero e emancipação humana, do $\mathrm{CNPq}$ em parceria com a pesquisa $A$ mulher nas organizações de cultura popular e a preservação dos valores tradicionais", aprovado pelo CNPq, no edital 045/2005 - Relações de Gênero, Mulheres e Feminismos, que desenvolvemos com pesquisadores da UFPE e da UFSC.

* Professora /pesquisadora do mestrado em Sociologia e do doutorado em Letras

da UFAL. E-mail: brcmagalhaes@gmail.com.

** Aluno do Programa de Pós-Graduação em Sociologia no Instituto de Ciências Sociais da Universidade Federal de Alagoas - UFAL. E-mail: gabriel bolinha@hotmail.com.

Latitude, vol. 3, n¹, pp.76-95, 2009.

DOI: https://doi.org/10.28998/2179-5428.20090105 
Belmira Magalhães

Gabriel Magalhães

culture, gender and social inequalities.

\section{Introdução}

Este artigo se propõe a debater a última proposta de ação do Governo Lula na área da cultura, enfatizando como esse tipo de programa tem como pressuposto uma tentativa de solução para o desemprego dos jovens. Na verdade, percebe-se que como o "programa primeiro emprego", enfatizado durante a penúltima campanha presidencial e colocado em prática nos primeiros meses da atual gestão, não conseguiu resultados satisfatórios, opta-se, então, por programas que, ressaltando a necessidade de respeito à diversidade cultural brasileira, acabam por "formar" uma mão-de-obra barata para o atendimento de necessidades locais de algumas comunidades majoritariamente localizadas nas periferias das cidades.

Enfocaremos essa problemática a partir de uma análise da proposta do Programa Cultura Viva e da aplicabilidade do programa em Pontos de Cultura de Maceió que concorreram ao primeiro edital e receberam recursos financeiros e tecnológicos. ${ }^{2}$

O artigo enfatizará o tratamento da cultura como fonte de renda para a população pobre. A atitude oficial aparece sempre dúbia, ressaltando a importância da cultura e, ao mesmo tempo, atrelando-a às manifestações populares apenas no processo de saneamento do desemprego, principalmente entre os jovens.

[...] todo mundo elogia o valor das artes: talvez surpreendentemente não seja mais ouvida a voz vigorosa e sem papas na língua que declara que gastar dinheiro em cultura é um desperdício de dinheiro honesto. Por outro lado, o governo defende as artes apenas em termos de vantagem econômica e de utilidade social estreitamente concebidas. A beleza e a glória não são mais termos do vocabulário político (JENKYNS, 2007).

A análise dos pontos de cultura enfatizará a participação das mulheres nesse programa, procurando perceber as contrariedades das relações de gênero, que não estão apenas nas condições biológicas dos sexos, mas em relações que

\footnotetext{
${ }^{2}$ As conclusões aqui apresentadas foram possíveis a partir do projeto de extensão Apoio à gestão dos Pontos de Cultura de Maceió, com ênfase no fortalecimento da atuação das mulheres na construção, preservação e difusão dos valores que sustentam a identidade de suas comunidades, financiado pela PROEX - UFAL2, integrado ao projeto de pesquisa $A$ mulher nas organizações de cultura popular e a preservação dos valores tradicionais", aprovado pelo CNPq no edital 045/2005 - Relações de Gênero, Mulheres e Feminismos, que desenvolveremos em parceria com pesquisadores da UFPE e da UFSC.
} 
reproduzem condições de dominação determinadas pelas relações de classes, reproduzindo desigualdades de gênero e de etnia. O gênero aporta em si as relações sociais na sua dialética e na articulação com outras relações.

Compreender as marchas e contramarchas vivenciadas pela mulher em seu processo de afirmação de identidade é, para Bahia e Ferraz (2000), vital para a construção de uma sociedade igualitária. Na sociedade brasileira, o fortalecimento da mulher enquanto sujeito político ativo tem um forte crescimento no processo de redemocratização, como aliás de todo o movimento sindical e reivindicatório. Multiplicam-se os movimentos de mulheres que denunciam não só as desigualdades de classe, mas também questões específicas da condição de mulher (FARAH, 2004; SANTANA, 2000).

Ao refletir sobre essa problemática, debruçando-se empiricamente num conjunto de organizações culturais reunidas sob um programa governamental de cultura, educação e cidadania como é o Programa Cultura Viva - e os Pontos de Cultura, especificamente - do Ministério da Cultura, este artigo pretende oferecer uma contribuição para avaliação da eficácia e efetividade deste Programa, enfatizando seus limites enquanto solução para a crise de emprego vivida pela sociedade brasileira, em especial, pela população jovem.

\section{O Programa Cultura Viva}

Numa primeira aproximação da proposta do programa Cultura Viva, percebe-se que há uma exaltação da identidade nacional e uma ênfase na cultura popular, que, segundo o texto realiza um diálogo "entre as expressões genuinamente brasileiras, como as indígenas e quilombolas, e aquelas recebidas de outros países". Percebe-se uma retomada, evidentemente de uma forma contemporânea, da problemática que deu origem à Semana de Arte Moderna em 1922, que enfatizava a busca das raízes do Brasil. Através dos Pontos de Cultura, o Programa pretende fazer com que os "artistas populares" consigam "materializar sua criatividade também, em produtos audiovisuais e digitais, usando a tecnologia".

$\mathrm{Na}$ verdade, percebe-se desde os primeiros parágrafos do discurso do Programa Cultura Viva o objetivo de relacionar as expressões culturais locais com o processo global de socialização, representado aqui pelas modernas tecnologias e formas de gestão.

O programa propõe, a partir de grupos já existentes, a entrega de tecnologia para que as manifestações possam ser divulgadas: uma proposta de cidadania cultural, a partir da valorização da cultura local. Nesse sentido, não há proposta de nenhuma mudança efetiva nas condições objetivas de vida dessa população. Embora o programa se refira à relação entre cultura e economia, a 
Belmira Magalhães

Gabriel Magalhães

proposta se limita à doação desses recursos eletrônicos e de bolsa ${ }^{3}$ para os participantes jovens, por seis meses.

Há uma exaltação nos objetivos do programa de se moldar à realidade, não impondo nada: "Trata-se, pois, de um programa flexível, que se molda à realidade, em vez de moldar a realidade". O que significa isso? Significa que o programa não oferece efetivamente nenhuma forma de mudança da realidade em que se encontra essa população, que, na verdade, não conseguiu até agora nenhum tipo de cidadania, a não ser o voto em cada eleição. As entrevistas com os organizadores dos pontos de Maceió mostram a grande dificuldade de manutenção dos jovéns nas atividades dos Pontos, uma vez que esses não podem se dedicar integralmente ao programa, pois precisam, de alguma forma, conseguir trabalho.

O fato fundante dessa realidade e da proposta dos pontos de cultura é a vinculação que o programa faz com o Programa Primeiro Emprego, bandeira da campanha de Lula (para presidente em 2002) que não saiu do papel. Na verdade, os grupos que se dedicam às expressões artísticas e culturais passam a ter como finalidade a "capacitação profissional" e propõem que a centralidade da cultura seja a forma de "transformação social" e do "desenvolvimento sustentável". A cultura passa a ser vista como geradora do emprego e renda e, em conseqüência, de resgate de cidadania.

Como se pode resgatar o que nunca se teve? O texto do Cultura Viva refere-se aos dois Brasis não para acabar com eles, mas para aproximá-los e fazer uma repactuação entre eles, isto é, a manutenção das desigualdades, mas agora com um pouco de cultura popular. Na verdade, esse tipo de proposta é a mesma inserida na propaganda do Programa Fome Zero: "O Brasil que come, ajudando o Brasil que tem fome". Com o uso do gerúndio observa-se que se estabelecem dois Brasis que vão se perpetuar, e um continuará "ajudando" o outro. Da mesma forma que a cultura popular ficará restrita e localizada, a cultura erudita universal cada vez mais se restringe a uma elite culta. ${ }^{4}$

Há toda uma filiação do programa à ideologia da pós-modernidade, cuja premissa é a de que a desigualdade é intrínseca à sociedade humana e que por isso temos apenas de fazer políticas compensatórias para essas populações 5 . Sabe-se que os produtos oferecidos pelos pontos de cultura e pelas artes locais em geral não podem competir no mercado efetivo, então reserva-se para eles a produção artesanal e a venda em pontos turísticos, fazendo com que essa população tenha uma ocupação e permaneça na mesma situação periférica da sociedade. Em nenhum momento o projeto propõe o intercâmbio com a cultura erudita,

3 Essas bolsas não deram os resultados desejados, complicando inclusive o funcionamento de alguns pontos, e foram retiradas a partir do segundo edital.

${ }^{4}$ Ver análise de Magalhães, 2006 mimeo.

5 Ver os outros programas do governo Lula. 
fabricando um discurso de resgate da cultura popular que deixa essa cultura exatamente no mesmo lugar: vista como prosaica, "coisa para turista ver", própria dos trópicos.

O programa cria a expressão os sem-Estado, e assinala que o Cultura Viva deseja contribuir para a operacionalização do Estado ampliado. Na verdade, o discurso do programa, aparentemente, paira fora das metas do governo que o sustenta, que em todas as ações aprofunda a diminuição da abrangência do Estado $^{6}$, proposta em todas as reformas do governo: universitária, trabalhista, previdenciária etc., quando preconiza a ampliação do Estado. No entanto, uma leitura mais apurada, a partir da materialidade discursiva (intradiscurso) ${ }^{7}$, atentando para o que é silenciado ${ }^{8}$ no discurso, faz perceber que essa ampliação ocorre no âmbito das políticas públicas compensatórias apregoadas pelo governo: bolsas, tecnologia e aprendizado profissional. Finalizada a participação do jovem no programa, não há emprego, restando para ele apenas o engajamento em outros projetos ou a participação em grupos ou atividades que gerarão uma renda mínima, que aprofundará os problemas quando se tornar adulto. Não há proposta de mudança do lugar social dessas pessoas.

Coloca-se um artista no Ministério da Cultura, elabora-se um programa que aparentemente pode ser aplaudido, pois traz a ideologia do resgate da cultura popular, mas acaba-se deixando tudo no mesmo lugar, sem nenhuma modificação da política econômica que causa o desemprego e a precariedade dessa população. Alguns assistidos pelos pontos poderão ter êxito e servirão de propaganda político-ideológica, mas a maioria permanecerá na mesma ou em situação ainda mais desvantajosa. E o que é pior, serão avaliados como incompetentes, pois tiveram oportunidade e não aproveitaram. Sabemos que não há possibilidade de absorção desses jovens, com a lógica política-econômica adotada pelo governo que criou o Cultura VIVA.

Quando se afirma que a cultura, através do sentimento de pertença, leva homens e mulheres a resgatarem sua humanidade, a referência é ao sentimento de pertencimento ao gênero humano como um todo e não apenas ao pertencimento localizado que, na verdade, apenas divide, em nome da diferença. Quando não se realiza a ligação entre o universal e o particular, corre-se o risco de gerar fundamentalismos de todas as espécies.

\section{A participação das mulheres nos pontos de cultura de Maceió}

\footnotetext{
${ }^{6}$ Manutenção da política monetária e das privatizações é uma das ações desse governo.

7 É na materialidade discursiva que o intradiscurso, isto é, as marcas lingüísticas que nos levam aos interdiscursos (discursos outros que atravessam o discurso), se constitui. Ver Pêucheux (1988).

${ }^{8}$ Para discussão sobre o silenciamento, ver Orlandi (1997).
} 
Belmira Magalhães

Gabriel Magalhães

A participação das mulheres nas atividades dos Pontos analisados - tanto à frente deles como beneficiada por eles - mostra sua importância no chamado terceiro setor. Muitas são as mulheres que estão dirigindo os Pontos, ao mesmo tempo que buscam, a partir desta posição, atuar contra o machismo ainda reinante na sociedade.

\begin{tabular}{|l|r|}
\hline \multicolumn{2}{|c|}{ Percentual de mulheres } \\
\hline Boi de Carnaval & $0 \%$ \\
\hline Graciliano é uma graça & $90 \%$ \\
\hline Guerreiros da vila & $70 \%$ \\
\hline Ideário & $70 \%$ \\
\hline Poleiro dos Anjos & $50 \%$ \\
\hline Quilombo & $80 \%$ \\
\hline
\end{tabular}

Podemos detectar, todavia, que esta ampla participação feminina muitas vezes fica aquém do que poderia fazer no combate desses elementos machistas entranhados na cultura popular. $O$ protagonismo das mulheres em vários casos não questiona determinadas características culturais que estereotipam a mulher na sociedade, apesar de entre os Pontos que têm as mulheres à sua frente esse questionamento se mostrar mais evidente do que naqueles dirigidos por homens. $\mathrm{O}$ protagonismo cultural tem por anseio preservar manifestações que fazem parte da história de um grupo e dar sentimento de pertença aos seus partícipes, no entanto, esse pertencimento não pode ser discriminatório.

Podemos observar que os Pontos não possuem atividades específicas para mulheres, apesar de a presença feminina nas atividades dos Pontos ser bastante expressiva - participação aqui enquanto beneficiadas. Com exceção do Ponto Boi do carnaval, todos possuem uma participação feminina bastante considerável, todavia, o grande problema existente é que nenhum deles possui um trabalho de conscientização dos jovens, no sentido de quebrar barreiras culturais à participação das mulheres, permitindo assim que o coordenador do Ponto Boi de Carnaval afirme: “(...) mas nas oficinas de boi de carnaval não tem participação feminina não. É clube do Bolinha".

Através da análise das falas dos coordenadores dos Pontos podemos constatar a carência de questionamentos que rompam o ideário popular que reproduz o "machismo" na sociedade. Em nenhum momento os integrantes dos pontos e seus coordenadores demonstraram conhecimento sobre a problemática de gênero e, ou menos, a percepção da discriminação que ocorre nas atividades que desempenham. Durante as oficinas realizadas com os coordenadores sobre a temática de gênero, percebia-se a surpresa dos membros do grupo em relação aos questionamentos feitos durante as atividades.

O número de mulheres que estão à frente das atividades dos Pontos é bastante expressivo; em relação às atividades destinadas aos jovens podemos observar que nenhum ponto afirmou que houvesse atividades especificamente para as mulheres: todas estão abertas para qualquer um participar, seja homem ou 
mulher. Todavia, não detectamos nenhuma atividade que tenha por objetivo pôr em questão/reflexão a existência do machismo na sociedade, especificamente na segregação por gênero que evidenciamos em várias formas de manifestação cultural. O que muito se verifica é a realização de atividades culturalmente definidas como masculinas ou femininas, sem que haja qualquer ação por parte dos pontos para alterar esta realidade preconceituosa. Algumas falas dos coordenadores dos Pontos para avaliar as oficinas realizadas pelos pesquisadores explicitam que, após estas, a reflexão se deu tanto de forma reprodutora quanto questionadora do machismo. Dois exemplos:

1- Continuo achando que o machismo deve existir sim entre um casal maduro, só que a mulher deve ter seu espaço respeitado. Eu não me assusto com a independência feminina, mas com a troca de papéis que isso pode causar.

2- Alerta para a possibilidade, que às vezes fica esquecida, de constantemente avaliar a postura machista que se estabelece no meio em que estamos inseridos, tentando sempre reverter esta situação, ampliando a discussão para igualdade entre gênero e o não-rebaixamento da mulher.

Na sociedade urbana contemporânea três dimensões subsidiam a definição de família: a sexualidade, a procriação e a convivência. Completando essa dimensão, podemos afirmar que na esfera simbólica a família é o lugar da intimidade e da afetividade. No mundo urbano formam-se duas esferas bem diferenciadas:

1- o lugar da produção, do trabalho; o espaço da rua; o lado de fora;

2- o lugar da reprodução biológica, da afetividade, da família; o espaço da casa; o lado de dentro.

A reprodução social determina as tarefas necessárias à manutenção do sistema, que agora vão ser executadas em espaços diferenciados: a reprodução biológica e cotidiana será realizada pela família no espaço da casa e a reprodução econômica e legal será feita no espaço da rua, nas fábricas e órgãos públicos da administração e de poder.

Essas mudanças, no início, pouco alteram as relações simbólicas familiares. Os homens continuam sendo os chefes da "casa", com poder de decisão sobre todos os assuntos, mesmo considerando que na maioria dos estudos realizados há indicação de que poucos são os trabalhadores que conseguem, apenas com seu salário, manter a família. $\mathrm{O}$ trabalho dos filhos e até de filhas solteiras vem complementar a renda necessária/possível para a sobrevivência de todos. Às mulheres casadas cabem tarefas sempre efetuadas no âmbito doméstico (lavagem de roupa, doces, costuras etc.). Não há mudança no modelo familiar nem nas relações de gênero.

Essa situação se desestabiliza quando as mulheres casadas passam a realizar tarefas fora do espaço da casa. Embora não haja redistribuição com os 
Belmira Magalhães

Gabriel Magalhães

homens, das tarefas e responsabilidades da reprodução cotidiana pelos homens só o fato da ausência da esposa/mãe no espaço doméstico ameaça a estruturação familiar aparentemente perene.

Generaliza-se, então, a dupla jornada; a responsabilidade com os cuidados dos filhos não é repassada nem quando a família faz uso de creches e outros mecanismos, pois admitir que as tarefas de reprodução cotidiana não são eminentemente femininas seria considerá-las desvinculadas da natureza da mulher, o que proporcionaria um rompimento com a construção simbólica que, desde a Antigüidade, afirma ser a função do útero e da amamentação o único determinante do lugar social feminino. Paralelamente, essa aceitação significaria a necessidade de viabilizar o trabalho doméstico e de computá-lo como horas gastas na manutenção da reprodução do sistema, o que acarretaria grandes perdas para a lógica do capital. ${ }^{9}$

O caminhar da humanidade tem sido sempre uma busca para além das leis biológicas e, paralelamente, principalmente nos últimos séculos, uma busca incessante de uma individuação que, ao mesmo tempo em que expressa uma sociabilidade, torna possível a realização de desejos individuais. A modernidade prometeu isso; no entanto, reduziu a individualidade à possibilidade de venda da força de trabalho em um mercado dominado pelo capital e com uma instituição jurídico-política que reafirma a supremacia de uma classe sobre as outras. ${ }^{10}$

A constituição de uma subjetividade autônoma ainda encontra sérios obstáculos para o gênero feminino, na medida em que representa a negação de estruturas simbólicas que a fazem dependente do outro sexo, pois, ao mesmo tempo que busca a autonomia, a mulher se sente responsável pelo bem comum familiar. Cria-se uma luta entre os diferentes membros da família em busca de suas próprias individuações, cabendo à mãe/esposa o papel de zelar pelo coletivo. A realização pessoal/profissional só será aceita quando não acarretar problema para o bom andamento da casa. Por isso, muitas mulheres desistem e só se encaminham para essa busca por necessidade financeira ou quando os filhos não precisam mais de assistência diuturna, e nunca deixam de se responsabilizar pelo bom andamento do lar.

Ambigüidade não é falha, defeito, carência de um sentido que seria rigoroso se fosse unívoco. A ambigüidade é a forma de existência dos objetos da percepção e da cultura, percepção e cultura sendo, elas também ambíguas, constituídas não de elementos ou partes separáveis, mas de dimensões simultâneas que, como dizia ainda Merleau-Ponty, somente serão alcançadas por uma racionalidade, para

\footnotetext{
${ }^{9}$ Ver Chauí (1986).
}

${ }^{10}$ Ver Marx. (1995). 
além do intelectualismo e do empirismo (Chaúí1986:123).

A ambigüidade é vista como possibilidade de ultrapassagem do passado e de reconstituição de um futuro diferente do presente. A maternidade compartilhada e a divisão das tarefas de reprodução da vida cotidiana representam a construção de novas bases para o casamento e, conseqüentemente, para a estrutura familiar, permitindo a cada membro da família um desenvolvimento enquanto ser autônomo.

Para que isso seja possível de se concretizar é necessário que novas relações sociais que incluem a mudança nas relações de gênero se coloquem como possibilidade concreta de realização. Isto implica a revisão do conceito de feminino, ligado a um dos lados da dicotomia razão/emoção e à desnaturalização das funções de reprodução da cotidianidade doméstica. Parir é uma função ligada diretamente ao sexo feminino; extrapolar essa característica para as funções de maternagem e domesticidade é uma criação ideológica que até hoje vem cumprindo a função de reproduzir o sistema capitalista de forma satisfatória para os dominantes.

$\mathrm{Na}$ verdade, cada sociabilidade precisa de individualidades condizentes com sua processualidade e ela vai gestar essas individualidades. A conclusão é que ainda faz sentido para o modo de produção capitalista manter a individualidade da mulher sob a submissão masculina. Lógico que agora o discurso é outro; o que se percebe é um discurso esquizofrênico em relação a homens e mulheres. Dizem aos indivíduos que eles podem tudo, basta querer. Para as mulheres dizem que elas já se emanciparam e são senhoras de suas próprias vidas e, paralelamente, afirmam ser necessário manter-se sempre jovem, fazendo plástica, estando sempre bonita, porque senão não será escolhida por ninguém, ou, quem sabe, trocada por outra em melhor "estado de conservação".

Por um lado, os discursos apregoam "vão para rua, vão ocupar o lugar a que têm direito". Enfim, afirmam que a mãe que não amamenta está prejudicando seu filho, logo não é boa mãe. Como amamentar, durante o tempo que a medicina estipulou como necessário, se as horas de atividade e de deslocamento para o trabalho ocupam grande parte do dia? O que fica dessa dupla mensagem? O sentimento de culpa, por não estar fazendo aquilo que é vital para o filho. $\mathrm{O}$ discurso é dúbio o tempo todo, porque dúbia a situação. A ideologia chama a mulher para o mercado de trabalho porque a mão-de-obra é mais barata, menos reivindicativa, mas não pode deixar de frisar que o lugar primordial ainda é a manutenção da reprodução do tipo de família e de indivíduo.

Reproduzindo essas colocação percebe-se, por exemplo que No ponto Graciliano é uma Graça várias atividades foram quase que exclusivas das mulheres em decorrência do preconceito reproduzido pela sociedade: os cursos de fuxico e cabeleireiro praticamente não contaram com a participação masculina, visto que tais atividades são tidas como "femininas" pela sociedade. 
Belmira Magalhães

Gabriel Magalhães

\subsection{A Análise da realidade dos Pontos de Cultura de Maceió}

A pesquisa que deu suporte para o presente artigo pautou suas análises nos seis Pontos de Cultura da capital alagoana, sendo estes selecionados no primeiro edital lançado pelo Ministério da Cultura (Programa Cultura Viva do Ministério da Cultura). São eles: Anima Alagoana (Boi de Carnaval), Graciliano é uma Graça, Guerreiros da Vila, Ideário, Poleiros dos Anjos e Quilombo dos Orixás. Vale frisar que o Programa Cultura Viva tem os Pontos de Cultura como o seu principal ator, além de que todos os Pontos tinham de ser entidades que trabalhavam com a cultura anteriormente ao programa. Sobre isso diz o programa: "Em lugar de determinar (ou impor) ações e condutas locais, o programa estimula a criatividade, potencializando desejos e criando situações de encantamento social". Segue abaixo a lista dos Pontos analisados na pesquisa, bem como o ano de sua fundação:

\begin{tabular}{|l|c|}
\hline \multicolumn{2}{|c|}{ Ano de fundação da entidade } \\
\hline Anima Alagoana (Boi de Carnaval) & 1998 \\
\hline Graciliano é uma graça & 2002 \\
\hline Guerreiros da vila & 1996 \\
\hline Ideário & 2002 \\
\hline Poleiro dos Anjos & 1980 \\
\hline Quilombo & 1984 \\
\hline
\end{tabular}

Os Pontos de Cultura como principal sustentáculo do Programa Cultura Viva forneceram dados importantíssimos para a análise desta política pública do governo federal. Apesar de se tratar de uma política do MinC que explicitamente tem por objetivo potencializar as manifestações culturais regionais, três dos seis Pontos investigados afirmaram que a área principal de suas atuações não é a cultura. Observemos:

\begin{tabular}{|l|l|}
\hline \multicolumn{1}{|c|}{ Pontos } & \multicolumn{1}{c|}{ área de atuação } \\
\hline Boi de Carnaval & Cultura alagoana \\
\hline Graciliano é uma graça & Formação profissional \\
\hline Guerreiros da vila & $\begin{array}{l}\text { Formar professores na área } \\
\text { ambiental }\end{array}$ \\
\hline Ideário & Comunicação e cultura \\
\hline Poleiro dos Anjos & Educativa e social \\
\hline Quilombo & Religião Afro \\
\hline
\end{tabular}

Tais dados mostram que as atuações dos Pontos estão sendo orientadas, em muitos casos, para fins estranhos ao objetivo primeiro do Programa. Isso nos leva a crer que o Estado - mediante o repasse da quantia destinada aos Pontos - está se eximindo de uma série de atribuições constitucionalmente definidas como de sua 
incumbência, como formação profissional e educação ambiental, transferindo-as para a sociedade civil através dos Pontos. Evidencia-se, neste caso, a manutenção ou até ampliação do modelo político neoliberal sob a égide do governo Lula, onde a política pública de um ministério historicamente periférico - no sentido de recursos - é destinada ao fortalecimento de ONGs como forma de amenizar o encurtamento das ações do Estado para a sociedade.

Vale frisar que o programa Cultura Viva enfatiza diversas vezes a liquidez da sociedade contemporânea; tal característica líquida da sociedade é transferida para a ação do Estado: não mais um Estado que de fora se impõe à sociedade, mas políticas públicas que se moldem à própria diversidade existente na sociedade, sendo essa postura sinônimo de democracia contra um passado marcado pelo intervencionismo estatal.

O programa é claramente baseado nesta perspectiva onde o Estado, sem qualquer projeto político-social global, ajuda as organizações da sociedade civil ${ }^{11}$ mediante transferência de recursos; a falta de um projeto amplo e sólido do Estado demonstra o seu caráter neoliberal, marcado por uma debilidade que é, ideologicamente, exaltada como vitória da democracia.

No que se refere ao público-alvo, os números mostram que os jovens são o grande objetivo dos Pontos, estando este em consonância com o Programa Cultura Viva, que define como público prioritário os "adolescentes e jovens adultos em situação de vulnerabilidade social".

\begin{tabular}{|l|l|l|l|c|}
\hline \multicolumn{5}{|c|}{ Público-Alvo } \\
\hline Boi de Carnaval & - & Jovens & - & Idosos \\
\hline Graciliano é uma Graça & Crianças & Jovens & Adultos & Idosos \\
\hline Guerreiros da Vila & Crianças & Jovens & Adultos & - \\
\hline Ideário & Crianças & Jovens & - & - \\
\hline Poleiro dos Anjos & Crianças & Jovens & Adultos & - \\
\hline Quilombo & Crianças & Jovens & Adultos & Idosos \\
\hline Porcentagem & $83,30 \%$ & $100 \%$ & $66,70 \%$ & $50 \%$ \\
\hline
\end{tabular}

A atuação voltada para os jovens é com certeza o grande objetivo do programa, ficando, através do programa Agente Cultura Viva, definido nos seguintes termos: "O Agente Cultura Viva é a ação que se articula ao Ponto de Cultura para despertar no jovem o interesse em iniciar, futuramente, uma profissão relacionada à cultura." Este programa, que se articula aos Pontos de Cultura, repassa 150 reais durante 6 meses aos agentes, com a pretensão de que estes, ao absorverem a cultura local, venham a se tornar empreendedores culturais. Temos então uma pretensão profissionalizante explícita no programa com a especificidade na área cultural, para

${ }^{11} \mathrm{Na}$ área da Educação tem-se o PROUNI, que tem como objetivo implícito ajudar as universidade e Escolas de Ensino Superior privadas. 
Belmira Magalhães

Gabriel Magalhães

que os jovens posteriormente possam gerar renda para o seu sustento mediante a propagação cultural. Além disso, as bolsas concedidas demonstram mais uma vez o anseio do governo federal em repassar recursos para a sociedade civil, neste caso de gerar uma renda temporária para os jovens atendidos nos moldes similares aos programas assistencialistas (Bolsa Família). Tal repasse era realizado pelo Ministério do Trabalho em substituição ao malogrado Programa do Primeiro Emprego, um dos pilares da campanha de Lula em 2001. Este programa foi extinto nos editais seguintes, haja vista os enormes problemas que estavam ocorrendo com o repasse das verbas, ocasionando mal-estar entre a comunidade e os Pontos de Cultura.

Como salientamos, o programa Cultura Viva visa estabelecer uma relação quase que direta entre cultura e cidadania e cultura e economia. Nas palavras do ministro Gilberto Gil: "Nos primeiros dias de gestão, definimos que a ação do MinC se daria a partir de um conceito com três dimensões articuladas: cultura como usina de símbolos, cultura como direito e cidadania, cultura como economia". Através do sentimento de pertença proporcionado pela ação dos Pontos, vislumbra-se um acesso à cidadania e uma forma de sustentabilidade para os jovens. Esse autoreconhecimento identitário proporcionaria a conscientização dos atendidos enquanto cidadãos, ou seja, reconheceria os seus direitos e seus deveres através da preservação e difusão dos valores culturais; aliado a isso, esses se tornariam empreendedores culturais capazes de se sustentar.

Contudo, empiricamente o que se verifica é a impossibilidade de esses jovens atendidos se tornarem empreendedores culturais como prega o programa, não por incapacidade ou incompetência deles, mas por problemas estruturais que extrapolam o universo cultural. Dessa maneira, a dissociação do programa Cultura Viva do conjunto das políticas do governo federal muitas vezes leva a análises equivocadas a respeito do programa. Afinal, cidadania só é possível de ser alcançada por meio de uma política macroestrutural da qual faça parte a cultura, caso contrário tais termos se tornam palavras soltas no ar.

A cultura às vezes parece ser utilizada como forma de eclipsar os verdadeiros problemas a serem combatidos atualmente. A cultura como afirmação da diferença se torna conservadora quando inibe a visualização da relação indissolúvel existente entre o particular e o universal. Estes particularismos que exaltam a diferença por vezes conformam os indivíduos com a sua situação miserável, propondo para eles soluções inócuas justamente por desvincularem a relação existente entre a cultura e os demais complexos sociais.

\subsection{A voz dos Pontos de cultura}

A partir das entrevistas realizadas com os seis Pontos de Cultura envolvidos na pesquisa foram construídas sete temáticas que refletem as principais preocupações de seus integrantes:

1- a cultura como meio de transformação social;

2- a participação das mulheres nos Pontos; 


\section{Cultura vira emprego}

3- as bolsas para os participantes;

4- repasse das verbas/burocracia;

5-. pontão;

6- profissional de contabilidade;

7- estruturação da entidade antes de ser tornar Ponto de Cultura.

Para este momento analisaremos apenas os três primeiros itens. A cultura é tida por todos aqueles que estão à frente dos Pontos de Cultura como um excelente mecanismo para a transformação social, especificamente das comunidades atendidas. Através do reconhecimento identitário proporcionado pela cultura popular espera-se que os indivíduos adquiram um novo estímulo para agirem sobre a sua realidade.

\# "Às vezes a gente olha pra sociedade e às vezes ficamos sem esperança, e pra mim esse projeto é um fato concreto de oferecer um resgate, um diferencial para esses adolescentes, pois eu não tenho dúvida de que o jovem que passa por um processo desse, jamais ele irá sair daqui e procurar algo pior para ele. Ele começa a ver que tem direitos, se ver como gente, se ver como cidadão com valores e vai buscar coisas melhores." (Ponto Guerreiros da Vila).

\# "Olhe nosso principal objetivo, que inclusive tá na nossa missão que é gerar acesso a bens em formatos culturais. Ou seja, é produzir e socializar informações (...) é coisa mesmo de a gente produzir livro, filme, mas a gente quer também que esse livro, esse filme chegue na mão de quem tem pouco acesso a esse bem, a informação (...) bom nesse monte de especificidade, mas principalmente é isso." (Ponto Ideário).

Cultura está, nesse sentido, intrinsecamente relacionada com afirmação, inclusive no que se refere à cidadania. Esse auto-reconhecimento identitário proporcionaria a conscientização dos atendidos enquanto cidadãos, ou seja, reconheceria os seus direitos e seus deveres através da preservação e difusão dos valores culturais.

\# "Vários deles já formaram grupos já deles no sentido de fazer alguma coisa pelas crianças ou de querer participar da própria associação de moradores, de querer intervir comunitariamente, alguns deles já estão desenvolvendo alguma atividade. Nenhum deles arranjou emprego de carteira assinada, isso a gente sabe que é difícil. Ingressar no mercado de trabalho, que é 
Belmira Magalhães

Gabriel Magalhães

outra coisa que eu achava com essa história de bolsa (...), isso é complicado." (Ponto Ideário, p. 04)

\# "Temos como meta principal formar cidadãos conscientes dos seus direitos e deveres, promovendo a capacitação das crianças que são responsáveis pelas mudanças. É isso que a gente faz. Cidadãos conscientes de seus direitos e deveres através da arte." (Ponto Poleiro dos Anjos).

O ministro da Cultura, Gilberto Gil, deixa esse objetivo bem claro quando diz: "Nos primeiros dias de gestão, definimos que a ação do MINC se daria a partir de um conceito com três dimensões articuladas: cultura como usina de símbolos, cultura como direito e cidadania, cultura como economia". Reconhecimento como mecanismo de cidadania e sustentabilidade econômica em um contexto de extrema dificuldade, principalmente devido ao desemprego crônico.

\# "Acredito que as oficinas já têm geração de renda. Já tem uma equipe de circo que é convidada pra fazer eventos. Pretendemos transformar o bairro em ponto turístico. Um ecomuseu a céu aberto onde já estamos fechando parcerias com a secretaria de turismo para que possa trazer turistas aqui ao bairro. Porque pensamos em dividir o conjunto em 11 ilhas literárias que levam o nome de obras e de personagens de Graciliano Ramos. E através dessa visita os turistas possam conhecer as obras desse autor." (Ponto Graciliano é uma Graça).

\# "Se somos tão ricos assim e a gente não tira proveito disso. Pelo contrário, nós não fortalecemos essa riqueza e, pior ainda, trabalhamos pelo fortalecimento desta riqueza, nós não divulgamos essa riqueza. $\mathrm{E}$, pior ainda, a gente não consegue aproveitar essa riqueza como uma âncora para o turismo." (Ponto Boi de Carnaval).

\# "A gente pensa que pro turista a gente vai vender aquela imagem bonita do alagoanozinho bonitinho da Ponta Verde, malhado. Não, a cara do alagoano é aquela cara sofrida. Eu queria ver aquela cara estampada numa camisa e botar uma frase bem legal "Cultura", eu gosto é disso. Falta é você mexer na auto-estima do povo, sabe, começar a dar uns "tabefes" na cara do pessoal, dizendo: "acorde, fio da peste, enxergue sua cultura"." (Ponto Boi de Carnaval) 
Há uma completa identificação dos sujeitos discursivos em relação ao papel da cultura para a sociedade: a cultura apresenta-se como um instrumento com alto potencial de transformação imediata. Podemos verificar que todos têm o objetivo de atingir a auto-estima das pessoas ou comunidades atendidas, retirando-os de um estado de apatia e ignorância, restituindo-lhes aquilo que lhes pertence, mas que se encontra distanciado. O grande objetivo é o reconhecimento identitário daqueles que por diversas razões abandonaram os valores e manifestações típicas do seu povo, absorvendo a chamada "pseudocultura" que nada diz respeito a sua realidade.

\# “(...)então o trabalho da gente se deu muito no sentido assim, a informação como forma de ponderamento e de crescimento pessoal, pode se dizer assim e inverter essa apatia, essa vergonha que isso gerava na maioria dos jovens de periferia, eles tão todos sempre assim se colocando no papel de submissão e de envergonhamento. Trabalha muito com essa questão de auto-estima." (Ponto Ideário,).

Aqui residiria o aspecto transformador da realidade social através da afirmação cultural: reconhecer a própria diferença (especificidade cultural) implica a busca por cidadania e por melhorias nas condições de vida. Em outras palavras, de maneira geral todos os pontos articulam a cultura com a cidadania, pois se reconhecer como diferente acarreta também o reconhecimento como igual aos demais, como indivíduo que possui direitos e deveres iguais a toda a sociedade. Todavia, o reconhecimento cultural aliado à cidadania parece esbarrar muitas vezes na dura realidade socioeconômica do país atualmente, gerando uma visão empreendedora da cultura. A cultura passa a ser vista como um mecanismo de transformação na medida em que pode proporcionar um impulso ao turismo no Estado de Alagoas. Os pontos Graciliano é uma Graça e Boi de Carnaval parecem os mais entusiasmados com essa possibilidade. Dizem: "Pretendemos, visualizamos desde a construção do projeto é transformar o bairro em ponto turístico."

Esse potencial é ainda mais impulsionado, pelo menos é o que o governo, com a adoção do programa Agente Cultura Viva, com o qual os Pontos ganhariam bolsas a ser distribuídas entre os jovens atendidos como forma de incentivar a participação. Diz a cartilha sobre o referido programa: "A capacitação específica é definida pelo ponto de cultura e a coordenação do programa contribui com o acompanhamento em educação popular, empreendedorismo cultural e microcrédito. $\mathrm{O}$ objetivo é incitar a geração de renda nas próprias comunidades, a partir de uma economia solidária".

\# "A dificuldade é que todo mundo entrou despreparado. Eu nunca tive preparado pra burocracia, pra fazer prestação de conta. O ministério não explicou 
Belmira Magalhães

Gabriel Magalhães

direito o perfil da prestação de conta. A gente foi aprendendo assim (...) como é que faço isso, como é que eu faço aquilo. A questão do kit também. Nós tivemos que nos adequar ao jeito que eles queriam. Nós temos que ter um técnico (contador) pra fazer isso. O medo também de errar e ser tachado de corrupto." (Ponto Poleiro dos Anjos).

\# “Agora é a mais turbulenta por falta de recursos que não vêm. Eu mandei minha prestação de conta no fim de julho, começo de agosto, e perderam e depois de um mês de ninguém dizer nada eu procurei saber e eles tinham perdido. Aí eu fiz outra prestação de conta e em novembro eu mandei, mas eles ficaram me pedindo documentos, documento... Disseram que havia chegado o último documento que eles queriam, mas desde novembro a gente está aqui sem dinheiro. Então a parte turbulenta está sendo agora." (Ponto Poleiro dos Anjos).

Vale frisar que a esperada "geração de renda (...) a partir de uma economia solidária" não se concretizou, pois a almejada introdução no mercado de trabalho se mostrou impossível. Sobre isso diz Ideário: "Nenhum deles arranjou emprego de carteira assinada, isso a gente sabe que é difícil. Ingressar no mercado de trabalho, que é outra coisa que eu achava com essa história de bolsa (...), isso é complicado".

Podemos afirmar que as bolsas tiveram como objetivo suprir a nãoefetivação do Projeto Primeiro Emprego do primeiro mandato do governo Lula. O programa Agente Cultura Viva foi uma forma encontrada de se transferir recursos para os jovens devido à função da recusa por parte do empresariado em efetivar o programa inicial. É consenso entre os Pontos de Cultura analisados que este programa não conseguiu atender aos seus objetivos e que, por isso, deve deixar de participar dos novos editais do programa.

Todas as entidades atendidas pelo projeto já possuíam atividades anteriormente, sendo um pré-requisito para que pudessem se tornar Ponto de Cultura. Podemos observar que há um sério problema no que diz respeito à gestão e à contabilidade dos atuais Pontos de Cultura.

\section{Conclusão}

A análise do Programa Cultura Viva e da sua efetivação prática através dos Pontos de Cultura de Maceió proporciona elementos significativos que permitem se concluir, de forma inequívoca, pelo caráter neoliberal desta política pública do governo federal. A tal conclusão poderia se chegar somente mediante a análise do Programa, com todo o seu discurso pomposo e até de certa forma rebuscado, mas a vivência com a sua dimensão efetiva proporcionou elementos que vieram 
reafirmar as conclusões da leitura do Programa, bem como acerca do protagonismo das mulheres nas atividades dos Pontos. Entre o segmento artístico e entre os agitadores culturais muito se afirma que a política definida pelo governo Lula para a cultura possui distinção substancial para com aquela realizada no governo FHC. Tal distinção residiria na substituição de uma política que beneficiava apenas expressões artísticas distantes das camadas populares, como as grandes peças teatrais, por uma que focaliza seu objetivo na cultura popular, no protagonismo daqueles que até então se encontravam à margem dos recursos federais.

Como se pretendeu mostrar acima, a grande política pública voltada para a cultura do governo federal não tem como objetivo aproximar os dois pólos da expressão da cultura - tomada de uma forma ampla; ao contrário, visa tão-somente manter esta cisão de caráter elitista em que a expressão popular se reproduz na sua mera particularidade, impossibilitada de apreender o húmus cultural legado pela humanidade e, conseqüentemente, impossibilitada de se afirmar. A cultura popular resta a subsistência proporcionada pelo repasse das verbas, da mesma forma que para ampla parcela dos trabalhadores brasileiros restam a(s) bolsa(s) assistenciais.

É óbvio que isso não se dá explicitamente, mas mediante uma elaboração que exalta o caráter cidadão do Programa. Assim, a cultura passa a ser vista como um meio direto para a inserção dos jovens na sociedade: o empreendedorismo cultural. Fecha-se o ciclo ideológico: após louvar a capacidade de afirmação identitária da cultura popular, havia a necessidade de demonstrar que a cultura muda a vida, isto se dando através da utilização da cultura como meio de ascensão social. Quando não se altera a vida, efetivamente há a impreterível necessidade de se introjetar a idéia de que a ascensão social é possível, mesmo que de maneira precarizada, sem carteira de trabalho e outros direitos.

À guisa de conclusão, pode-se definir o Programa Cultura Viva como uma continuidade de um projeto político-ideológico que se efetiva em todas as esferas sociais, através das políticas públicas para a saúde, educação, esporte, entre outras. Para se tornar plausível perante os beneficiados, desvincula-se a relação indissolúvel existente entre cultura e a sociedade como um todo, entre esta política pública específica e a política econômica do governo. Somente assim ela pode ser encarada como um meio direto de democratização, como uma forma de ascensão social.

Paralelamente, percebe-se o engajamento das mulheres nos Pontos de cultura, reafirmando seu papel maternal, agora como cuidadoras dos jovens, sem nenhuma reflexão sobre as relações de gênero e as marcas da opressão feminina realizada pelo patriarcalismo. Reproduzem-se os lugares sociais através da cultura, como fazem o Boi de carnaval e outros pontos, que separam as atividades desenvolvidas por meninos e meninas.

Apela-se para as diferenças culturais como forma de enfatizar a diversidade sem nenhuma mudança das relações sociais. Exalta-se o diferente para deixá-lo no mesmo lugar: pobre, sem educação qualificada, sem emprego e sem cultura universal. 
Belmira Magalhães

Gabriel Magalhães

\section{Bibliografia}

BADINTER, Elisabeth. Palavras de Homens.Tradução de Maria Helena F. Martins.Rio de Janeiro: Nova Fronteira,1991.

BARBOSA, Regina Maria e PARKER, Richard (org.) Sexualidades pelo Avesso: direitos, identidades e poder. São Paulo: Ed.34,1999.

BONACCHI, Gabriella e GROPPI, Angela. (org). O dilema da cidadania. Tradução de Álvaro Lorencini. São Paulo: Universidade Estadual Paulista,1995.

BOURDIEU, Pierre. La domination masculine. Paris: Ed. Di Seuil, 1998.

BOURDIEU, Pierre. O Poder Simbólico. 3ae ed. Rio de Janeiro: Berthand Brasil, 2000.

BOURDIEU, Pierre. A Economia das Trocas Sombílicas. 5a ed. São Paulo: Editora Perspectiva, 1999.

BOURDIEU, Pierre. HAACKE, Hans. Livre Torca. Rio de Janeiro: Berthand Brasil, 1995.

BOURDIEU, Pierre. O Desencantamento do Mundo. São Paulo: Perspectiva, 1979.

BOURDIEU, Pierre. Razões Práticas. Sobre a Teoria da Ação. $2^{2}$ ed. Oeiras: Celta editora, 2001.

BOURDIEU, Pierre. Sociologia. São Paulo: Ática, 1983.

BOURDIEU, Pierre e WACQUANT, L. J. D. An invitation to reflexive sociology. Chicago; Chicago University Press, 1992.

BURITY, Joanildo (org,) A. Cultura e identidade: perspectivas interdisciplinares.Rio de Janeiro:DO\&A, 2002.

BAHIA, M. C. dos A.; FERRAZ M. A. V. Entre a Execução e a Regra: a contrução do feminino na política baiana. Em: Organizações e Sociedade. Salvador: EDUFBA, v.7. n.18, 2000.

CANCLINI, N. G. As Culturas Populares no Capitalismo. São Paulo; Brasiliense, 1982.

CANCLINI, N. G. Consumidores e Cidadãos: conflitos multiculturais da globalização. Rio de Janeir: Editora da UFRJ, 1999.

Latitude, vol. 3, n¹, pp.76-95, 2009. 
Cultura vira emprego

CASTRO, Rocio. Gênero e participação Cidadã para o Desenvolvimeto local: os conselhos municipais de Salvador - Bahia. Em: Organizações e Sociedade. Salvador: EDUFBA, v.6 n.16, 1999.

CASTRO, Mary Garcia. Marxismo, feminismo e feminismo marxista - mais que um gÊnero em temposneoliberais. Revista de Crítica Marxista, 2000, vol:11, p. 98-108.

EAGLETON, Terry. As Ilusões do Pós-modernismo. Rio de Janeiro; Jorge Zahar Editores, 1998.

FAIRCLOUGH, Norman. Discurso e mudança social. Brasilia, Ed. UnB, 2001.

FAHAR, Marta F. S. Gênero e políticas públicas. Revista de Estudos Feministas. Abr. 2004, vol. 12.

FEATHERSTONE, Mike(org.) Cultura Global. Nacionalismo, Globalização e Modernidade. 2ª ed. Rio de Janeiro; Vozes, 1998.

FEATHERSTONE, Mike(org.) Cultura Global. Nacionalismo, Globalização e Modernidade. 2 ${ }^{\underline{a}}$ ed. Rio de Janeiro; Vozes, 1998.

HOLANDA, Heloisa Buarque de. Tendências e impasses; o feminismo como crítica da cultura. Rio de Janeiro: Rocco,1994.

KARTCHEVSKY, Andrée et.alii. O sexo do trabalho. Rio de Janeiro, Paz e Terra,1986

LUKÁCS, Georg. O Trabalho. Tradução de Ivo Tonet. Maceió: 1997, mimeo.

MAGALHÃES, Belmira et alii. Magistério: reprodução da discriminação feminina. Curitiba:HD Livros,1996.

MAGALHÃES, Belmira et alii. Mulher: gravidez, saúde e Estado. Curitiba, HD Livros,1997.

MAGALHÃES, Belmira. As Marcas do corpo contando a História: um estudo sobre a violência doméstica. Maceió,EDUFAL, 2005.

MARX, Karl. Glosas críticas marginais ao artigo. Tradução de Ivo Tonet. Revista Praxis, n. 5, Belo Horizonte: Projeto Joaquim de Oliveira, 1995.

MARX, Karl A questão Judaica. São Paulo Moraes, 1991.

MÉSZÁROS, István. Filosofia, ideologia e ciência social: ensaios de negação e afirmação. São Paulo: Ed. Ensaio, 1993. 
Belmira Magalhães

Gabriel Magalhães

MÉSZÁROS, István. Educação para além do capital. http://resist.info

ORLANDI, E As formas do silêncio. 4.ed. São Paulo: Unicamp,1997.

PÊCHEUX, M.Semântica e discurso.Campinas, UNICAMP,1988.

PEREIRA, Carlos Alberto [et al.] (org.). Linguagens da Violência. Rio de Janeiro:Rocco,2000.

PIRRUCCI, Antônio Flávio. Ciladas da diferença. São Paulo: Ed. 34,1999.

PRADO, Danda. Ser esposa: a mais antiga profissão.São Paulo: Brasiliense,1979

ROCHA, Maria Isabel Baltar (org.). Trabalho e gênero: Mudanças permanências e desafios. São Paulo: ED.34, 2000.

SAFFIOTI, Heleieth I.B. O poder do Macho.São Paulo: Moderna,1987.

TONÉ, Ivo. Mercado e liberdade. Maceió: EDUFAL, 1997.

WANIER, Jean Pierre. A Mundialização da Cultura. Lisboa. Editora Noticias, 2000. 